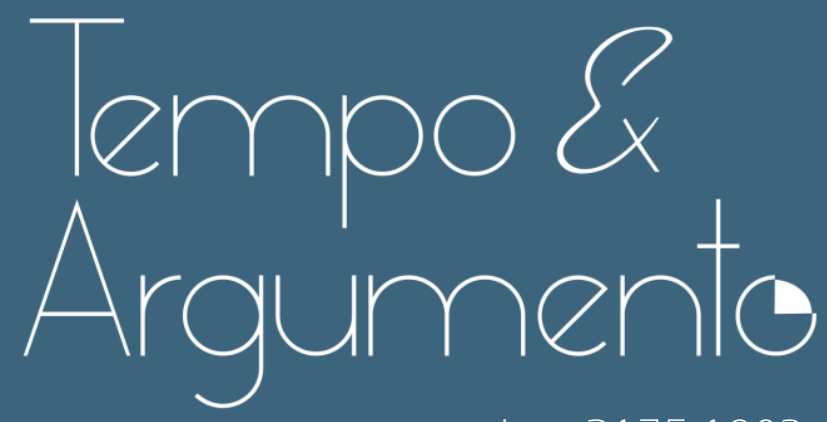

e-issn 2175-1803

O acesso de mulheres indígenas à universidade: trajetórias de lutas, estudos e conquistas

- Rosângela Célia Faustino

Doutora em Educação pela Universidade Federal de Santa Catarina (UFSC).

Professora da Universidade Estadual de Maringá (UEM).

Maringá, PR - BRASIL

lattes.cnpq.br/8578533833560165

rcfaustino@uem.br

(D) orcid.org/0000-0002-8089-1450

- Maria Simone Jacomini Novak

Doutora em Educação pela Universidade Estadual de Maringá (UEM).

Professora da Universidade Estadual do Paraná (UNESPAR).

Paranavai, PR - BRASIL

lattes.cnpq.br/8950601840578036

maria.novak@unespar.edu.br

(D) orcid.org/0000-0002-3820-6579

- Isabel Cristina Rodrigues

Doutora em Ciências Sociais pela Pontifícia Universidade Católica de São Paulo

(PUC/SP). Professora da Universidade Estadual de Maringá (UEM).

Maringá, PR - BRASIL

lattes.cnpq.br/0643613119453873

icrodrigues@uem.br

(D) orcid.org/0000-0003-2973-4721

Para citar este artigo:

FAUSTINO, Rosângela Célia; NOVAK, Maria Simone Jacomini; RODRIGUES, Isabel

Cristina. $O$ acesso de mulheres indígenas à universidade: trajetórias de lutas,

estudos e conquistas. Tempo e Argumento, Florianópolis, v. 12, n. 29, e0 103 ,

jan./abr. 2020.

do: http://dx.doi.org/10.5965/2175180312292020e0103

Recebido: $31 / 08 / 2019$

Aprovado: 17/03/2020 


\title{
O acesso de mulheres indígenas à universidade: trajetórias de lutas, estudos e conquistas
}

\begin{abstract}
Resumo
Embora os povos indígenas requeiram "educação superior" no Brasil desde o final do século XIX demonstrando seu intenso protagonismo, data dos anos de 1990 a formulação da política de inclusão de indígenas nas universidades públicas. Neste artigo, discutimos trajetórias de resistência, lutas e demandas dos povos indígenas, que resultaram no acesso ao ensino superior, consubstanciado por orientações internacionais e legislações nacionais. Abordamos o papel e presença da mulher nesse processo discutindo dificuldades vivenciadas e ações que empreendem para ingressar e concluir a formação. Com base em estudo documental, pesquisa de campo e dados do programa de inclusão indígena no Ensino Superior do Paraná, conclui-se que as mulheres, mesmo com um histórico de invisibilidade e todas as dificuldades vivenciadas para acessar e permanecer nas universidades distantes das suas famílias extensas, têm obtido resultados relevantes em termos de conclusão dos cursos e ampliação dos seus espaços de atuação e participação.
\end{abstract}

Palavras-chave: Mulheres indígenas. Ensino superior. Protagonismo Indígena.

\section{The access of indigenous women to university: trajectories of struggles, studies and achievements}

\begin{abstract}
Although indigenous peoples have required "higher education" in Brazil since the end of the 19th century, demonstrating their intense leading role, the formulation of the policy for the inclusion of indigenous people in public universities dates from the 1990s. In this article we discuss trajectories of resistance, struggles and demands of indigenous peoples, which resulted in access to higher education, based on international guidelines and national legislation. We approach the role and presence of women in this process by discussing difficulties experienced and actions they under take to enter and complete their education. Based on documentary study, field research and data from the indigenous inclusion program in Higher Education in Paraná, it is concluded that women, even with a history of invisibility and all the difficulties experienced to access and remain in universities, away from their own extended families, relevant results have been obtained in terms of completing the courses and expanding the spaces for practice and participation.
\end{abstract}

Keywords: Indigenous women. Higher education. Protagonism. 


\section{Introdução}

Desde o final do século XIX, quando se intensificam as ações do governo brasileiro na política de expropriação, restrição dos territórios, aldeamentos indígenas e integração (GAGLIARDI,1989; MONTEIRO, 1994; MOTA, 1998), os povos indígenas passam a incluir, com mais vigor, em suas pautas de lutas, resistência e negociação, a educação escolar como uma estratégia para melhor conhecer e manejar as relações com o poder público. Movimento semelhante ocorre em diferentes períodos e países da América Latina, evidenciando estratégias indígenas para se profissionalizarem como professores, desde o século XVI (HARTMANN; OBEREM, 1981).

Vivendo sob regimes de escravidão, exploração colonialista e perda de territórios, os povos indígenas resistiram e lutaram contra todas as formas de expropriação e opressão buscando a manutenção de suas terras, suas organizações socioculturais e autodeterminação. No processo de conquista de direitos indígenas, que envolveu guerras e estratégias de consenso, foram séculos de resistência, até que passassem a ser considerados sujeitos de direitos e as mulheres indígenas, embora pouco retratadas pela historiografia, têm um papel ativo nas lutas (MOTA, 1998).

Durante as primeiras décadas do século XX, em resposta aos levantes indígenas, e diante de um cenário econômico e político que propiciava a elaboração de uma legislação abordando a diversidade cultural, registra-se a ampliação dos direitos das minorias. Estudos foram encomendados nos Estados Unidos, sistematizados no Meriam Report (1928), para o reconhecimento e respeito às culturas e línguas indígenas (COLLET, 2006).

Com o socialismo avançando desde a Revolução Russa, em 1917, que garantiu direito de sufrágio universal às mulheres e direitos linguísticos às minorias, oficinas internacionais na Europa foram organizadas para repensar a questão da educação das minorias étnicas e os seus direitos culturais e linguísticos (RIES; HUGUES; SAER, 1932).

O resultado dessas iniciativas se consolidou como política pública internacional no pós Segunda Guerra Mundial (FAUSTINO, 2011). Organismos internacionais como o Banco Mundial (BM), a Organização Internacional do 
Trabalho (OIT), Organização das Nações Unidas (ONU), a suas agências de cooperação técnica, como a Organização das Nações Unidas para a Educação, a Ciência e a Cultura (UNESCO), passaram a elaborar programas voltados às sociedades indígenas, formulando direitos internacionais, com recomendações sobre o reconhecimento das línguas e culturas minoritárias (UNESCO, 1950; OIT, 1957). A Comissão Econômica para a América Latina e o Caribe (CEPAL), criada em 1951, se encarregou de estudos e ações, direcionados aos povos indígenas na região.

Nos anos de 1980, no contexto de grande crise econômica do sistema de mercado, aumento da pobreza e reformas neoliberais (FAUSTINO, 2006), as lutas sociais se intensificaram e ganharam mais visibilidade. O movimento das Diretas já no Brasil, o levante do Exército Zapatista de Libertação Nacional (EZLN) no México, movimentos camponeses na região, a institucionalização do Movimento dos Trabalhadores Rurais Sem Terra (MST) e de inúmeros movimentos sociais indígenas, como os desenvolvidos na Amazônia, a partir de 1974 (CAVUSCENS, 2014), explicitaram uma pauta nacional de reivindicações por demarcação de terras, direitos constitucionais, equidade, saúde e educação indígena (OLIVEIRA FILHO; ROCHA FREIRE, 2006; MATOS, 2006; SILVA, 2014). Em resposta a essas grandes lutas sociais, com destacada participação indígena, os governos da região, para consolidar as medidas neoliberais, controlando as resistências, iniciaram reformulações jurídicas (RAMOS, 2012), e a elaboração de políticas públicas de inclusão para os povos indígenas.

Conforme Verdum (2008), o movimento brasileiro de mulheres indígenas começa a se configurar no mesmo período, com o surgimento de lideranças femininas que fizeram-se ouvir por órgãos governamentais nacionais e internacionais. Nesse processo, as mulheres indígenas, mesmo vivendo majoritariamente em sociedades de tradição patrilinear, em zonas rurais, com pouco acesso à educação básica e superior, informações e tecnologias, tiveram papel fundamental, pois exercem poder político e religioso em suas comunidades e buscam parcerias em diferentes espaços como ONGs (OLIART, 2012), igrejas, universidades, passando a ser alvo de ações governamentais prioritárias. 
Essas forças sociais impulsionaram reformas constitucionais em todo o continente (RAMOS, 2012). Ampliaram-se os direitos de cidadania e o acesso de diferentes segmentos sociais às políticas públicas. Houve mudança constitucional no Panamá em 1971, no Brasil em 1988, na Colômbia em 1991, em El Salvador em 1992, na Guatemala, Paraguai e México em 1992, no Peru em 1993, na Argentina, Bolívia e Equador em 1994. A partir das mudanças nas leis maiores, esses países passaram à elaboração de uma legislação complementar, para a implantação de programas focalizados na área da educação, saúde e manutenção das línguas minoritárias, em consonância com orientações dos organismos internacionais (ONU, 1992).

Dessa forma, este artigo se caracteriza como um estudo de caso (MINAYO, 2000), no qual discutimos algumas das trajetórias de resistência, lutas, alianças e negociações dos povos indígenas com a sociedade envolvente, que resultou na formulação de políticas de ações afirmativas para acesso ao ensino superior, cujas bases estão fundamentadas em eventos e documentos dos organismos internacionais que orientam políticas e legislações nacionais.

Por meio de revisão bibliográfica, estudos documentais e de campo, abordamos o papel e presença da mulher nesse processo discutindo percursos de lutas, organizações e conquistas do ensino superior no Paraná, bem como as dificuldades vivenciadas e as estratégias empreendidas para a permanência e conclusão da formação superior.

A pesquisa de campo foi realizada no período de 2013 a 2015, no âmbito de um projeto financiado pelo CNPq, por meio do Edital do MCTI/CNPq/SPMPR/MDA no 32/2012, e contou com observações e entrevistas semidirigidas ${ }^{1}$ com mulheres indígenas provenientes de diferentes etnias e terras indígenas no Paraná, que ingressaram em cursos de graduação no estado pelo programa de inclusão indígena nas universidades (PAULINO, 2008; NOVAK, 2007, 2014; RODRIGUES; WAWZYNIAK, 2011). Priorizou-se nas entrevistas os temas: escolha da área, estratégias de permanência nos cursos, dificuldades encontradas nas

\footnotetext{
${ }^{1}$ A pesquisa foi autorizada pelo Comitê de ética, conforme Processo Número CAAE: 8435312.9.0000.0104. Número do parecer de aprovação do CONEP: 505.818. Número do parecer de aprovação do COPEP/UEM: 633.
} 
cidades e nas aldeias após se matricularem, relações com as famílias/comunidades, preconceito, problemas e ou conquistas que quisessem narrar.

\section{Uma política internacional de inclusão e atenção à mulher indígena}

No Brasil, entre o final do século XIX e as primeiras décadas do século XX, os territórios indígenas já estavam praticamente ocupados em sua totalidade e, políticas de pacificação e integração foram elaboradas (SILVA NOVAK; MOTA, 2016) no sentido de conter os movimentos e lutas indígenas pela manutenção de suas terras tradicionais.

Concomitante às estratégias para a manutenção das formas de vida tradicionais, os indígenas empreenderam ações para o acesso ao conhecimento científico e domínio de tecnologias como a escrita, conforme atesta um documento do Ministério dos Negócios da Fazenda do Rio de Janeiro (BRASIL, 1973, p. 112), que indefere pedido de "pensão" feito por lideranças indígenas, de um aldeamento de Cabo Frio, por meio de ofício enviado ao governo provincial, pedindo "educação superior" aos jovens indígenas aldeados.

No contexto dos aldeamentos, a escrita passou a ser uma das "armas" usadas pelos indígenas em suas estratégias de resistência. Mota (1998, p. 203) expõe uma carta reportada pelo etnólogo Hebert Baldus, produzida por chefes indígenas Kaingang, no sul do Brasil, por meio da qual denunciam a invasão das áreas demarcadas pelo governo, pedem proteção contra ameaças e violências empreendidas por fazendeiros da região, bem como ajuda material ao poder público e garantia dos acordos e direitos indígenas estabelecidos.

Por influências do indigenismo internacional (GAGLIARDI, 1989), o Brasil, após a proclamação da república, aderiu a tratados e convenções, criando órgãos específicos como o Serviço de Proteção ao Índio e Localização de Trabalhadores Nacionais (SPILTN), em 1910, substituído, em 1967, pela Fundação Nacional do Índio (FUNAI), encarregados pela tutela indígena.

As ações foram orientadas, tanto pelos programas do Instituto Indigenista Interamericano, criado na América Latina em 1940, como por estudos sobre 
cultura e diversidade, encomendados pela UNESCO (1950), e regulamentados em convenções internacionais como a Convenção no 107 da Organização Internacional do Trabalho, OIT (1957). Dos anos de 1960 a 1980, documentos e estudos da CEPAL apresentados em conferências internacionais (DURSTON, 1979) demonstram a formulação de uma política de educação e desenvolvimento, voltada aos povos indígenas da região, baseada na integração econômica e cultural.

Para Wieviorka (1999, p. 20), a partir dos anos de 1970, assistiu-se no mundo inteiro, à emergência de exigências de afirmações identitárias provenientes de grupos diversificados, que podem ser definidos em termos religiosos, étnicos, raciais, históricos, de origem nacional, de gênero, de deficiência física, de doenças graves etc. Para o autor, em certos casos, essas exigências e expectativas culturais estão direta e fortemente associadas às desigualdades sociais, à grande exploração no trabalho e ao desemprego estrutural criado pela reforma neoliberal.

Resistências e levantes indígenas nos anos de 1980, como os que o Exército Zapatista de Libertação Nacional (EZLN) empreendeu no México, colocam, com mais visibilidade, a questão dos direitos da mulher nas sociedades indígenas, ensejando novas políticas que se consolidam a partir de então.

O movimento internacional das mulheres formulou e apresentou pautas de inclusão, explicitadas, por exemplo, no I Congresso Mundial de Mulheres por um Planeta Saudável, ocorrido em Miami em 1991. Eventos internacionais como a Conferência das Nações Unidas sobre Meio Ambiente e Desenvolvimento, conhecido como Rio-92, apontaram a importância do conhecimento e do papel da mulher no desenvolvimento sustentável. Concedeu-se um prêmio internacional à Rigoberta Menchú, no ano de 1992, consolidando-se aí uma plataforma de discussão sobre o reconhecimento, a valorização e os direitos das mulheres.

Estudos encomendados pelo Banco Mundial, revelaram a exclusão e a pobreza das populações indígenas demonstrando que esses povos estão entre as camadas mais pobres da população sendo os "mais pobres entre os pobres" (BANCO MUNDIAL, 2000; BENGOA, 1993; PARTRIDGE; UQUILLAS; JOHNS, 1996; 
PSACHAROPOULOS; PATRINOS, 1993). Um dos fatores apontados como sendo o responsável por essa situação foi a falta de acesso a políticas de saneamento, saúde, educação e informação.

Os estudos atestaram que, historicamente, as políticas públicas não alcançam os grupos indígenas. Psacharopoulos e Patrinos (1993) evidenciam que essas comunidades situam-se abaixo da linha de pobreza, são discriminadas e têm poucos direitos de participação na cidadania, situação causada, dentre outros, pela falta de escolaridade adequada com níveis de acesso e formação suficientes.

Outros diagnósticos informam o coeficiente da pobreza entre as populações indígenas gerando maior necessidade de uma educação que priorize a permanência das mulheres na escola e o acesso à informação para a melhoria da qualidade de vida dos grupos.

Há uma quantidade relativamente limitada da atenção colocada atualmente na participação de mulheres indígenas [...] dado o papel chave que as mulheres indígenas desempenham na transmissão de línguas e culturas indígenas, assim como o acesso mais limitado de meninas indígenas à educação primária e secundária em muitos países Latino Americanos, mais atenção deve ser prestada aos problemas de gênero em todos os aspectos do esboço, da execução e da avaliação dos projetos. (DAVIS, 2003, p. 8)

Segundo Ruiz (2002, p. 256), diante deste panorama, organizações internacionais estabeleceram metas para a redução da pobreza por meio de programas com diretrizes bem definidas: uma das principais é a necessidade imperiosa de considerar o aspecto "gênero" como um dos fatores importantes para o combate à pobreza e exclusão.

Segundo o Relatório de Desenvolvimento Humano (PNUD, 2014, p. 3) "Os povos indígenas, que correspondem a cerca de 5 por cento da população mundial, representam cerca de 15 por cento dos pobres do mundo, um terço dos quais em situação de pobreza rural extrema”. Os estudos da Organização Internacional do Trabalho (OIT, 2007, p. 45), evidenciam que: "Os jovens indígenas estão entre os grupos mais vulneráveis e desprotegidos. De acordo com diversas estimativas, os indígenas na América Latina flutuam entre 30 e 50 milhões". 
A CEPAL informa que:

La información disponible sobre los pueblos indígenas en América Latina muestra, en forma sistemática y sostenida, que experimentan una mayor incidencia de la pobreza, reciben menores ingresos, tienen menor escolaridad, menos años de esperanza de vida, mayor mortalidad infantil y materna, así como un menor acceso al saneamiento y el agua potable. (CEPAL, 2013, p. 14).

O organismo declara ainda, na mesma linha de dados, que "El grupo más rezagado en términos de escolarización es el de los jóvenes de 18 a 22 años, com bajos porcentajes de asistencia a instituciones educativas, que em ningún país de La región superan el 40\% (el rango va de un 24\% en México a un 40\% en Costa Rica)" (CEPAL, 2013, p. 14).

Em decorrência dessas informações divulgadas na região, as políticas atuais, conforme a Declaração e Plataforma de Ação da IV Conferência Mundial Sobre a Mulher, coordenada pela ONU, informam que deve-se prestar apoio às atividades econômicas das mulheres indígenas, valorizar seus conhecimentos tradicionais, visando à melhoria de sua situação e favorecimento de seu desenvolvimento.

O intuito dessas ações é promover e fortalecer políticas e programas que permitam a maior participação das mulheres indígenas, de maneira que tenham oportunidades e possibilidades de opção nos processos de desenvolvimento, melhorando a eficácia dos programas de aliviamento da pobreza, voltados para os grupos de mulheres desfavorecidas.

Segundo SACCHI (2003; 2005), há, cada vez mais, uma maior participação das mulheres indígenas em encontros, oficinas e conferências nacionais e internacionais promovidos pelas organizações indígenas e instâncias estatais ou não governamentais, propiciando o fortalecimento de suas organizações e a troca de experiências, bem como a gradativa capacitação para o exercício na esfera pública.

Seguindo as orientações da Conferência Mundial sobre Educação Superior da UNESCO de 1998, o Ministério da Educação (MEC) reafirmou a necessidade de “[...] fazer do Ensino Superior um espaço de maior inclusão e equidade social, 
como perspectiva de democratização e impacto econômico e social" (UNESCO, 1998, p. 15). Conclamou universidades a definirem políticas de equidade que possibilitem novos mecanismos de apoio à inclusão, com estratégias de promoção de equidade, garantindo acesso para estudantes de baixa renda e para segmentos da população com menor ingresso, tais como indígenas, negros, pessoas com necessidades educacionais especiais e residentes em zonas rurais. "A integração destes grupos ao ensino superior é elemento-chave do seu processo emancipatório, como oportunidade de formação pessoal e também coletiva" (UNESCO, 1998, p. 15).

As políticas públicas de inclusão dos povos indígenas na universidade e atenção às mulheres estão baseadas nessas recomendações, nas quais defendese a necessidade de reconhecimento e apoio ao direito das mulheres e das meninas indígenas à escolarização, bem como a promoção de uma educação que atenda às necessidades, aspirações e culturas indígenas, mediante a elaboração de programas educativos, planos de estudo e meios didáticos apropriados nas línguas das populações indígenas; com a participação das mulheres indígenas nesses processos.

\section{Mulheres indígenas no Paraná}

No Paraná, historicamente, vivem três sociedades indígenas: os Kaingang, os Guarani e os Xetá. Nos processos de ocupação dos territórios, promovidos desde os primeiros movimentos de colonização europeia, essas sociedades tiveram grande parte de suas terras expropriadas e muitos grupos foram dizimados em projetos de exploração da região. Os indígenas, no entanto, resistiram, lutaram e sobreviveram como povos culturalmente diferenciados (MOTA, 1998; RODRIGUES, 2012).

Conforme dados do Censo Demográfico (IBGE, 2010) esses povos representam uma população de cerca de 25.000 (vinte e cinco mil) pessoas no Paraná vivendo em pequenas áreas demarcadas - as Terras Indígenas - que não thes permitem mais a sustentabilidade da forma tradicional, de acordo com suas culturas. Em decorrência disso, o Censo identificou que parte dessa população 
vive nas cidades, para onde muitas famílias migram devido a conflitos ou, em busca de trabalho e melhores condições de existência.

Nessas sociedades indígenas a mulher tem papel e atuação relevante na política da aldeia; opera na rede familiar mantendo a unidade e boa parte do sustento do grupo, responsabilizando-se pelo cuidado com crianças e jovens, e com os mais velhos. Mesmo vivenciando realidades excludentes e desiguais, por meio da linguagem oral, do trabalho e demais atividades cotidianas, as mulheres indígenas têm papel fundamental na transmissão, às novas gerações, de elementos identitários e linguísticos, de suma relevância à sua preservação histórica e cultural.

O povo Kaingang, classificado como Jê Meridional, é a etnia mais numerosa na região, e se concentra em 15 (quinze) Terras Indígenas (TI). Os Guarani, pertencentes ao tronco linguístico Tupi, somam cerca de 4000 (quatro mil) pessoas e vivem em 19 (dezenove) TI sendo as comunidades formadas por grupos menores. Em algumas situações, os Guarani foram aldeados em Terras junto com os Kaingang havendo hoje muitas famílias misturadas, cujos filhos podem ser Guarani mas falar apenas o Kaingang (devido à descendência patrilinear), ou ser Kaingang e falar a língua Guarani. E o povo Xetá, também do tronco linguístico Tupi, é constituído por cerca de 220 (duzentas e vinte) pessoas, a maioria, vivendo na TI São Jerônimo, junto com os Kaingang e Guarani, enquanto aguarda a demarcação oficial de seu território reivindicado na região de Umuarama, no oeste do Paraná.

Essa realidade também problematizou o recorte da pesquisa, na medida em que, ao realizarmos o trabalho de campo com uma lista do rol das mulheres indígenas Kaingang que se inscreveram no Vestibular do Paraná, no período de 2002 a 2012, nos deparamos com situações em que algumas se declararam Kaingang na Ficha de Inscrição do Vestibular, mas, ao serem entrevistadas se identificaram como Guarani, devido ao fato de estarem casadas com homens Guarani e terem filhos que seguem a descendência patrilinear.

Situações ao contrário também foram identificadas em campo: mulheres Guarani, casadas com homens Kaingang e que frequentam, na mesma TI, tanto a casa de reza Guarani e demais atividades culturais, identificando-se com elas 
em sua rede de parentesco; como as assembleias Kaingang para discutir questões políticas e sociais que envolvem a vida na comunidade, o que demonstra identidades em constantes dinâmicas. Há mulheres Xetá casadas com homens Guarani e outras casadas com homens Kaingang que se relacionam ativamente nos três grupos étnicos.

Com base nessas informações, a pesquisa abarcou mulheres indígenas em suas distintas dinâmicas culturais que influenciam na formação superior e atuação dessas mulheres em aldeias no Paraná.

A situação sociolinguística nas TI no Paraná é diversificada e tem relação com o histórico da ocupação do território e das lutas pela demarcação da terra que, muitas vezes eram oficialmente indígenas, mas ocupadas por colonos, não índios, fato que acarretou em muitos casamentos entre índios e não-índios. Há Terras em que predomina o uso da língua indígena em todas as situações cotidianas, Terras em que o bilinguismo é acentuado e outras em que a língua portuguesa se impôs como primeira língua. Todas as comunidades buscam, a partir dos direitos expressos na Constituição Federal de 1988, e reforçados em legislações posteriores, a revitalização e o fortalecimento das línguas e culturas indígenas, bem como a introdução à educação escolar para acessar os conhecimentos universais.

Como as terras demarcadas apresentam solo desgastado pelo reuso e rios poluídos pelas atividades do entorno, muitas famílias vivem em situação de extrema precariedade, e sem renda fixa. Geram renda por meio do trabalho com artesanato (atividade restrita à disponibilidade de matéria-prima que rareia em todas as áreas demarcadas), com serviços temporários, quando os encontram nas fazendas da região, por meio de políticas públicas como o Programa governamental Bolsa Família, além de algumas aposentadorias e empregos públicos existentes nas aldeias.

No Paraná, em todas as atividades que geram renda, as mulheres indígenas conduzem ou têm participação ativa. São responsáveis pela coleta de taquara, cipós, sementes e plantas para a produção do artesanato, trabalham em casa e nas roças familiares, preparam os alimentos de toda a família extensa, cuidam dos filhos, produzem e comercializam artesanato nas cidades, organizam times 
de futebol (atividade de encontros e socialização muito importante nas aldeias do Paraná), participam das igrejas que existem nas aldeias, buscam orações e curas para doenças de seus filhos e familiares, acompanham-nos em tratamentos de saúde, fazem partos, ajudam a preparar velórios e festas, participam das assembleias comunitárias e começam a compor conselhos de educação e saúde nos grupos das lideranças tradicionais.

O documento La Participación de las Mujeres Indigenas em La Conservación del Patrimonio Cultural, elaborado pelo Comité de América Latina y el Caribe para la Defensa de los Derechos Humanos de la Mujer (CLADEM) afirma que:

Gran parte del patrimonio cultural de las comunidades indígenas de la región, incluyendo el conocimiento de la medicina, las propiedades de las plantas, semillas y hierbas medicinales; lo que brinda la vida animal, las tradiciones orales, los diseños que se aplican em las artes visuales, las cerámicas y textiles que incluyen símbolos ancestrales; se há conservado gracias al esfuerzo de las mujeres. (CLADEM, 2014, p. 2).

Desde a infância, as meninas indígenas ocupam diferentes espaços nas aldeias e em seus grupos familiares. Estão mais frequentemente acompanhando as atividades da mãe e assumem, com pouca idade, tarefas relacionadas aos cuidados com irmãos e primos pequenos, trabalham com artesanato e preparação de alimentos. Frequentam a escola, casam-se quando têm por volta de 13 a 16 anos e passam a assumir as responsabilidades também com seus filhos e companheiros e, são as responsáveis diretas pelo ensino da língua materna. Essas ações, conjugadas, conferem às mulheres indígenas um papel de destaque em suas comunidades e estas têm buscado, dentro das difíceis conjunturas em que vivem, novas formas de inclusão social, efetivação e ampliação dos direitos à cidadania.

O programa de acesso dos povos indígenas ao ensino superior no Paraná

A implementação dos primeiros cursos específicos para a formação superior indígena, em âmbito nacional, considerando as determinações e 
orientações dos organismos internacionais, data dos anos de 1990 com as Licenciaturas Interculturais criadas em Instituições Federais de Ensino Superior, em diferentes regiões do Brasil. No estado do Paraná, a partir do ano de 2001, com a Lei Estadual n. 13.134, os indígenas aqui territorializados, tiveram acesso efetivo ao ensino superior, por meio de vagas suplementares criadas nas sete universidades públicas estaduais, e, em 2006, estendida à Universidade Federal do Paraná (NOVAK, 2007; 2014).

Considera-se, esta, uma iniciativa pioneira e diferenciada em relação a grande maioria das ações de inclusão indígena no ensino superior do país, que primam pela oferta de Licenciaturas Interculturais. Nestas, a formação acadêmica é diferenciada e específica, assim como o período de estudo que, geralmente se organiza pela alternância em Tempo Escola e Tempo Comunidade, o que possibilita não apenas uma maior valorização das culturas e línguas indígenas como maior interação, trocas e aprendizagens entre os estudantes indígenas de uma mesma turma.

As licenciaturas interculturais foram fomentadas pelo Programa de Apoio à Formação Superior e Licenciaturas Indígenas (Prolind), com quatro editais, lançados nos anos de 2005, 2008, 2009 e 2013. Segundo Marqui e Oliveira (2019, p. 34), "atualmente são ofertados 14 cursos de Licenciatura e Pedagogia Intercultural com aproximadamente 2.700 professores indígenas matriculados". As autoras apresentam uma discussão do Programa, a partir de suas atuações no Ministério da Educação e de experiências com os cursos de Licenciatura e Pedagogia ligados a ele, cujo foco é a "[...] formação superior de professores indígenas que atuam nos anos finais do ensino fundamental e ensino médio". (MARQUI E OLIVEIRA, 2019, p. 34). No Paraná, não se implantaram essas licenciaturas até o ano de 2018 (GEHRKE; SAPELLI; FAUSTINO, 2019).

Conforme a negociação das lideranças com o poder público, e um cenário internacional favorável à medidas de inclusão, formulou-se uma política de acesso ao ensino superior por meio de vagas suplementares, na qual indígenas podem escolher sua formação em uma ampla gama de áreas do conhecimento e cursos diferenciados, ofertados pelas Instituições de Ensino Superior (IES) 
(NOVAK, 2014), não se limitando à formação em uma única graduação e área do conhecimento e atuação.

Porém, essa forma de ingresso, em diferentes cursos no Paraná, enseja limites e dificuldades, tais como situações de isolamento e dispersão, baixo envolvimento das comunidades com a formação superior indígena, ausência de canais de interação e de conteúdos relacionados à história, culturas e línguas indígenas nas disciplinas cursadas, predominância da língua portuguesa nos estudos superiores, alto índice de reprovação por notas e faltas, trancamentos de matrícula, transferências de cursos, retenção nas séries, necessidade de retorno para as terras indígenas, desistência e abandono dos cursos.

Essas questões se expressam no baixo número de indígenas formados no ensino superior do Paraná. Em um período de 12 anos (2002-2014), por exemplo, dos 439 (quatrocentos e trinta e nove) indígenas aprovados no Vestibular dos Povos Indígenas, apenas 41 (quarenta e um) conseguiram se formar. Esse número representa uma conquista para povos que lutaram por mais de cem anos (BRASIL, 1973), pelo acesso ao ensino superior no Brasil, porém, é um percentual baixo de formação, o que denota uma qualificação, em termos numéricos, insatisfatória no Paraná.

Com uma política de inclusão e financiamento que completa 20 anos no estado, permanece uma ausência, generalizada, de profissionais indígenas graduados para assumirem postos de trabalho em suas comunidades, como por exemplo, nas 39 escolas indígenas nas quais atuam 825 professores, apenas 320 são indígenas e 509 não são indígenas (PARANÁ, 2019). Nossa pesquisa de campo, no âmbito do Programa Interinstitucional de Pesquisa e Formação Intercultural/Bilíngue de Professores Indígenas no Paraná (PROFIND), identificou, no ano de 2019, que, dos 320 professores indígenas, apenas 60 têm curso superior sendo alguns deles graduados em IES privadas, na modalidade de EaD.

Há duas ações unificadas para o acesso e permanência dos Estudantes Indígenas das IES no estado: o Vestibular dos Povos Indígenas no Paraná e o Auxílio Permanência ao Estudante Indígena, Resolução no. 23/2016-SETI/PR. Cada IES tem uma comissão específica para tratar da formação superior indígena, e, 
juntas compõem uma comissão estadual conforme a Resolução Estadual no․ 006/2007 (PARANÁ, 2007).

As universidades do Estado têm ações institucionais ou coordenadas por grupos de pesquisa da área, voltadas ao acompanhamento desses acadêmicos. No caso da Universidade Estadual de Maringá (UEM), há um Programa Interdisciplinar de Estudos de Populações/Laboratório de Arqueologia, Etnologia e Etno-História que desenvolve projetos de ensino, pesquisa e extensão envolvendo estudantes e comunidades indígenas das diferentes etnias (FAUSTINO; NOVAK; CIPRIANO, 2013). Há, também, na instituição, uma legislação específica para os estudantes indígenas, composta por Resoluções aprovadas pelo Conselho de Ensino, Pesquisa e Extensão (CEP) - Resolução no. 115/2006² e Resolução no. 205/200733, com um programa de acompanhamento dos estudantes indígenas, o Programa de Inclusão e Permanência de Alunos Indígenas (PROINDI), envolvendo coordenadores de cursos de graduação nos quais hajam indígenas matriculados, tutores e monitores. Essas ações têm contribuído com a permanência, avanço nos estudos e conclusão dos cursos.

Dos problemas identificados e ou reportados pelas/os estudantes (NOVAK, 2014), destacam-se a dificuldade de permanência nas cidades, a formação básica deficitária, a distância entre a universidade e a realidade das terras e culturas indígenas, a dificuldade de compreensão e produção de textos acadêmicos científicos, que são alheios às ciências, às línguas e aos conhecimentos indígenas.

Para as mulheres, esses problemas são potencializados pois, conforme a organização sociocultural das sociedades indígenas, elas tradicionalmente são responsáveis por muitas atividades no cotidiano da aldeia, sendo que sua presença é de suma relevância para a unidade das famílias extensas, provisão do sustento, saúde e educação dos filhos e cuidado com os mais velhos.

\footnotetext{
2 UNIVERSIDADE ESTADUAL DE MARINGÁ. Resolução CEP n. 115/2007. Aprova o Programa de Inclusão e Permanência de Alunos Indígenas (PROINDI), conforme anexo, parte integrante desta resolução. Maringá: UEM, 2007. Disponível em: http://www.scs.uem.br/2007/cep/115cep2007.htm. Acesso em: 14 abr. 2011.

${ }^{3}$ UNIVERSIDADE ESTADUAL DE MARINGÁ. Resolução CEP n. 205/2006. Normatiza o processo de ocupação de vagas, matrícula e acompanhamento dos alunos indígenas beneficiados pela Lei no 14.995/2006. Maringá: UEM, 2006. Disponível em:

http://www.scs.uem.br/2006/cep/205cep2006.htm. Acesso em: 04 abr. 2011.
} 
Diante dessa realidade, buscou-se compreender os percursos formativos de acadêmicas do ensino superior no Paraná que vivenciam a situação de serem mulheres provenientes de minorias étnicas, mas que entendem ser o ensino superior uma contribuição para a melhoria do acesso a renda, superação da exclusão e ampliação de seus espaços de atuação, tanto nas comunidades indígenas como na sociedade envolvente.

\section{Mulheres indígenas e seus percursos nas universidades no Paraná}

Os relatos das trajetórias de vida e as entrevistas mostram que as mulheres indígenas trilham um longo e tortuoso percurso para acessar, ingressar e estudar no ensino superior, conforme a disponibilidade dessa modalidade de ensino no Paraná. As descrições evidenciam uma realidade que se repete com frequência na vida das mulheres.

C.A. é uma estudante Kaingang de 26 anos, casada que tem 2 filhos. Aprovada no Vestibular Específico, se matriculou em três universidades no Paraná, trocou de curso quatro vezes: iniciou com Enfermagem, passou para Educação Física e depois ingressou em Pedagogia para optar, na quarta matrícula, pelo curso de Pedagogia a distância da UEM. Matriculada na EaD, retornou à aldeia para estar próxima de sua família, comprou um computador, organizou seus estudos com outras mulheres estudantes indígenas da mesma comunidade e viajava periodicamente para assistir aulas no Polo da EaD e tirar dúvidas com as tutoras. Conseguiu se manter matriculada, realizar todas as atividades do curso, tendo concluído o mesmo no ano de 2019 e, na sequência, assumido a direção da escola indígena. Relatou que no decorrer do curso teve muitas dificuldades de acesso à internet na aldeia, mas enfrentou e não desistiu de estudar.

J.S. é uma Guarani de 29 anos. Quando bem jovem, trabalhou em casa de família, na cidade próxima à aldeia. Morava com a família que trabalhava devido à ausência de transporte diário para retornar à aldeia e pelas necessidades de horário do próprio trabalho. Sendo o local de trabalho próximo, visitava a família com regularidade. Fez ensino fundamental na Terra Indígena e concluiu os estudos na cidade. Fez vestibular pela primeira vez no ano de 2006. Foi motivada 
por uma reunião que houve na aldeia, em que o cacique falou para as famílias que "queria gente da própria aldeia trabalhando na escola". (J.S., 2014. Informação verbal).

Em conversa com sua mãe, decidiu que iria estudar. Casou-se, no "casamento de índio" com um Guarani, também universitário, e teve dois filhos. Matriculou-se, primeiramente no curso de Informática em 2007, transferiu-se para Educação Física em 2008, onde ficou por quatro anos, retida na primeira série do curso. Transferiu-se para Letras em 2012 e, no mês da entrevista, junho de 2014, estava matriculada no segundo ano do curso, "puxando" algumas disciplinas nas quais reprovou no primeiro ano. Nessa época, teve vários problemas de saúde. Permaneceu matriculada por oito anos, tentando estudar, mas desistiu, compondo o rol estatístico de evasão.

E.N.C. é uma Kaingang proveniente de uma aldeia que só fala a língua Kaingang. Os adultos da comunidade sabem o português, mas o usam apenas em relações com a sociedade do entorno. E.N.C. é considerada pela família como boa aluna na escola, porque aprendia bastante e era muito participativa. Casouse bem jovem e teve uma filha. Provém de uma família dos troncos velhos; seu pai é liderança e seu irmão é professor bilíngue. Assim que terminou o ensino médio resolveu estudar na universidade. Ao fazer o Vestibular dos Povos Indígenas do Paraná, em 2009, ser aprovada e ingressar, mudou-se para a cidade, no Centro Cultural Indígena (ASSINDI), que disponibiliza algumas moradias e apoio à saúde e alimentação para mulheres artesãs e estudantes indígenas. Tendo se ausentado da aldeia para estudar, foi abandonada pelo marido que se casou com outra mulher e ficou com a guarda da filha conforme seu direito, estabelecido na legislação interna da aldeia, devido à descendência patrilinear Kaingang. E.N.C. desistiu dos estudos, retornou à aldeia, recompôs sua vida, e, depois de um tempo retornou à universidade trazendo o novo companheiro junto. Em 2019, completou 10 anos morando na cidade, tentando se formar no curso de Pedagogia presencial para retornar à sua comunidade de origem.

Nas narrativas sobre estudar e ser mulher indígena, as acadêmicas evidenciam elementos culturais e as lutas que empreendem para ingressar, permanecer e se formar. 
Porque a mulher quando ela entra na Universidade, ela já entra com filhos. A mulher fala menos que o homem então para a mulher é muito difícil. [...] Fala menos, até hoje você não vê mulher cacique, raramente tem. [...] É mais difícil para a mulher entrar, só que ela consegue se formar porque [...] Ela vai atrás, ela quer ter uma formação, o homem não. (C.B., 2014. Informação verbal).

Esse entendimento corrobora os dados. A UEM tem apresentado o maior número de estudantes formados no estado com a política da Lei 13.134/2001 (FAUSTINO; NOVAK; CIPRIANO, 2013). Como ação para melhorar a permanência, foi possibilitado o acesso indígena também aos cursos de Educação a Distância da instituição, que favorecem muito as mulheres pelas dificuldades que estas têm em sair das aldeias para residir em Maringá, município bastante distante das terras indígenas do estado. Em 2019, entre 24 concluintes, 16 são mulheres representando um percentual de 66,6\%, sendo destas, 15 casadas e com filhos quando do ingresso na IES.

O resultado da formação superior indígena na UEM e no Paraná, em geral, sendo maior entre as mulheres, evidencia suas lutas para buscar melhorias das condições de vida de suas famílias extensas. Com acesso à universidade, visam o melhor desenvolvimento em suas aldeias e, também, impulsionar as crianças e jovens, preparando-os com autonomia, para agenciar a vida dentro e fora das comunidades.

Pra mim, estudar é eu estar a par das coisas que estão acontecendo no mundo. Que nem eu que morei na terra indígena até ontem bem dizer né? É um lugar que ainda necessita de muita coisa, tem muita coisa que não tem lá, o povo não tem acesso, a nossa educação lá, ela também é fraca, porque na medida em que tem um professor indígena lá que ele é bom, que tem professores bons na terra indígena, eles vão ficando velho, vão aposentando, então pra mim a necessidade de estudar é grande e eu não quero ficar pra trás. Uma que se você não tiver o preparo adequado, você não consegue levar a comunidade pra frente, porque a comunidade, as pessoas que moram na comunidade elas não vão ficar ali pra sempre, não tem emprego pra todo mundo ali dentro da comunidade, uma hora elas vão ter que sair pra fora, é nessa hora que a gente tem que saber como lidar e ensinar essas crianças e esses jovem que tão saindo da aldeia pra trabalhar fora, como lidar lá fora. (S.V., 2014. Informação verbal). 
As necessidades das comunidades se manifestam, também, na escolha dos cursos superiores. Conforme C.B.:

Escolhi Enfermagem porque nas aldeias tem muita dificuldade, os indígenas que falam uma só língua eles têm dificuldade para falar sobre o problema para a enfermeira. Quem atende lá são só os não indígenas. Eu vi isso e ficava tão triste, mas é porque não tinha as pessoas formadas. Um exemplo: o Kaingang mesmo, não tem na minha aldeia quem atende. Lá é enfermeira não índia, então pra ela é uma dificuldade e para o indígena também, muito mais ainda. Eu via isso e escolhi esse curso para tenta ajudar as pessoas da minha comunidade. (C.B., 2014. Informação verbal).

As entrevistadas apontaram as necessidades das aldeias e os desafios da vida na universidade, principalmente os relacionados à falta de apoio nos cursos e nas salas de aula; insuficiência de recursos financeiros para se manterem nas cidades; pouco acompanhamento pedagógico, ou inadequado, pois ocorre de acordo com os padrões normativos de desempenho acadêmico quantitativo (resolver listas de exercícios, ler e interpretar textos), sem considerar as especificidades étnicas e culturais; rejeições e preconceitos; distância e tempo que permanecem longe da família e da TI.; dificuldade em conciliar as inúmeras atividades dos cursos com as atividades de ser mulher indígena, participar das lutas de seus povos e dar conta dos afazeres da esfera doméstica.

A vida das mulheres indígenas é permeada por elementos complexos,

[...] marcada pela sobrevivência em meio à pobreza, por conseguir que as crianças cheguem à idade adulta superando todos os tipos de doenças curáveis; pela desigualdade e aprisionamento às determinações masculinas; pela violência física dos homens, sempre acentuada pelo problema do álcool; pela dupla jornada de trabalho, realizando os trabalhos tipicamente femininos, mas também os trabalhos dos homens quando é necessário - quando o contrário não é verdadeiro. (SANTOS; SCHILLING, 2008, p. 87)

Porém, evidenciou-se nas narrativas, uma forte disposição para enfrentar essas dificuldades e desafios.

Eu queria muito fazer faculdade. Eu cheguei até aqui, lutei muito, deixei minha casa na aldeia, levei meu marido e minhas crianças comigo. Pra que? Não foi para voltar sem meu diploma. Vim, sofri, venci. Hoje sou enfermeira na minha aldeia com muito orgulho! (S.M., 2014. Informação verbal). 
Sobre ser mulher indígena formada, há dois aspectos que foram apontados: um positivo, pois a probabilidade de conseguir emprego na aldeia (escola, unidade de saúde) é grande, melhorando assim as condições de vida da família; e um negativo, no tocante às relações com o "homem índio":

Aqui é bem complicado porque o homem índio ele não gosta de ser mandado. Até quando eu entrei aqui, quando eu trabalhei aqui como supervisora na escola eu via essa diferença dentro daqui. Os professores índios falavam: poxa ela é uma mulher, nós temos que obedecer? Nós temos que fazer? É complicado. Mas eu acho que isso já vem lá de trás, de antes e isso é uma conquista que a gente tem que ter, tem que brigar bastante. (M.A., 2014. Informação verbal).

Verifica-se que as mulheres indígenas vêm reconstruindo, ressignificando e alargando os espaços de participação e atuação política, tanto internamente, nas Terras Indígenas, cujo cacicado, historicamente é ocupado pelos homens, como externamente, na sociedade brasileira, marcada pelo colonialismo patriarcal.

\begin{abstract}
Vai ter eleição, agora depois que saiu o último cacique. Eles falaram que não vai ter mais essa do cacique ficar mais tempo, pra sempre. A cada cinco anos vão trocar, aí vai ter eleição [...], eu também queria me candidatar [...]. Nós vamos colocar, nós temos já duas mulheres que faz parte da liderança indígena, mas quando sair as candidaturas, nós vamos colocar mulher. Nós já temos pessoas capazes de dirigir a comunidade, mulher. Eu queria me candidatar, mas vai ser difícil por que eu moro fora da aldeia. Por conta dos emprego, porque daí o pai trabalha a mãe trabalha, e antes tinha aquela história né? Que a mulher tinha que ficar na casa, sempre teve né? Só que a mulher começou tomar um como é que eu digo? Ela começou tomar um, num sei que palavra que eu posso te dizer, que elas, sei lá tomaram um jeito, tomaram um pensamento diferente que agora elas trabalham, elas tem 0 dinheiro delas, elas compram o que elas querem, elas gastam com o que elas querem, entendeu? (S.C.C. 2014. Informação verbal.)
\end{abstract}

Evidencia-se nas narrativas dessas mulheres que elas têm atuado na construção de um espaço cada vez maior de sua participação como protagonistas de novas pautas comunitárias. Porém, muitos são os desafios para os povos indígenas, sobretudo para as mulheres, ingressarem, permanecerem e concluírem o ensino superior, mas é uma luta que elas vêm travando e obtendo 
resultados, haja vista o percentual maior de concluintes mulheres, conforme verifica-se no Relatório do Vestibular Indígena no Paraná (PARANÁ, 2020, p. 37), que, no total de 101 indígenas formados pelas universidades estaduais, no perío do de 2002 a 2019, 81 são mulheres, o que equivale a um percentual de 80,19\% de concluintes do gênero feminino e 19,8\% de concluintes do gênero masculino.

Esses dados e os relatos das experiências e articulações, narradas pelas estudantes e egressas indígenas, permitem aferir que ingressar e concluir cursos de graduação tem sido uma importante estratégia adotada por essas mulheres gerando a conquista de maiores espaços de atuação profissional e política, tanto interna quanto externa às suas aldeias/comunidades indígenas. Elas têm assumido postos de trabalho nas terras indígenas - como professoras, pedagogas, coordenadoras pedagógicas, diretoras, enfermeiras, dentistas, assistentes sociais, médicas - anteriormente ocupados por não-índios.

Com os conhecimentos adquiridos nos estudos acadêmicos, ampliam seu protagonismo e inserem-se melhor nos espaços políticos nativos e nos movimentos etnopolíticos que empreendem externamente às aldeias. Conquistam visibilidade, garantem espaços e direito não apenas de fala, são ouvidas e respeitadas na condição de indígena mulher, estudante, profissional, ativista, militante e atuante nas históricas lutas políticas que os povos indígenas vêm travando desde a chegada dos povos estrangeiros, para garantirem junto com suas comunidades, os seus direitos duramente conquistados ao longo destes 520 anos de contato com a sociedade não-indígena.

\section{Algumas Conclusões}

O ensino superior tem sido um espaço que vem se tornando cada vez mais presente na vida das populações indígenas no Brasil, como forma de busca por conhecimentos, luta por igualdade e justiça social, diminuição do preconceito, maior espaço de atuação econômica e política em suas aldeias e junto à sociedade envolvente; inclusão e autonomia.

Muitos ainda são os desafios para esse nível de ensino, como melhoria das condições materiais acessíveis aos estudantes indígenas, ampliação dos valores 
dos auxílios, melhoria nas políticas de permanência, que devem ser respaldadas por estudos do perfil sociocultural das diferentes etnias, bem como ampliação do diálogo no âmbito do Estado para que as sociedades indígenas tenham maior espaço de participação na proposição e construção das políticas que os envolvem, exercendo, assim, seus protagonismos.

Nas sete IES estaduais públicas do Paraná, que apresentam milhares de servidores, não existe nenhum indígena atuando como professor/a, pesquisador/a, ou servidor/a técnico/a, efetivo/a. Há uma carência geral de linguistas, historiadores, geógrafos, matemáticos e outros profissionais indígenas - graduados e pós-graduados - que poderiam ocupar espaços de poder e decisão junto às secretarias estaduais e municipais, aos Núcleos Regionais de Educação - principalmente aqueles que jurisdicionam as escolas indígenas - e outros; para assim, com autonomia, melhor contribuir na formulação e condução das políticas públicas que thes envolvem.

Mesmo com as muitas dificuldades e o baixo número de estudantes formados/as no Paraná, os povos indígenas continuam lutando por esse espaço desafiador que é o ensino superior. Têm sido criadas novas modalidades nessa formação como a Educação a Distância, na UEM, e a consolidação, por algumas IES do estado, de cursos específicos e diferenciados - as Licenciaturas Interculturais - com a efetiva participação indígena, desde a formulação dos projetos até sua execução (GEHRKE; SAPELLI; FAUSTINO, 2019).

Estar na universidade enseja aprendizagens tais como comprar passagens, viajar para a cidade sozinha/o, acessar transportes urbanos, encontrar endereços, organizar documentos pessoais, preencher formulários de matrícula, ler as placas que sinalizam os campi universitários, encontrar os blocos, as salas de aula, o quiosque de reprografia, a pasta do professor, a biblioteca, o restaurante universitário, participar das aulas, aprender conteúdos acadêmicos, compor equipes de estudo, produzir e digitar trabalhos, ler e discutir textos científicos, participar de aulas práticas, fazer pesquisa, participar de debates, exercitar novas formas de comunicação e argumentação. Há, ainda, a possibilidade de visitar museus, shopping centers, almoçar fora, fazer novas amizades e alianças, arrumar emprego, conceder entrevistas aos meios de comunicação no Dia do 
Índio, fazer palestras em escolas, participar de eventos, aprender informática e a lidar com as ferramentas e ambientes virtuais de aprendizagem (AVA).

Ações que, para quem viveu 500 anos de colonialismo e tutela até 1988, quando a Constituição Federal thes concedeu a cidadania, são de suma relevância, principalmente em se tratando de mulheres indígenas que, historicamente ficaram restritas aos espaços domésticos. Todas essas aprendizagens compõem os resultados que os indígenas buscam no ensino superior, além do diploma.

Esse conjunto de resultados é a soma das muitas conquistas que se expressam no domínio dos modernos códigos da sociedade contemporânea, de suma relevância para pessoas provenientes de grupos expropriadas dos meios de produção da vida e altamente excluídas.

Após vivenciar a universidade e retornar à aldeia, narram, repassam, contam histórias aos seus familiares transmitindo experiências acumuladas, uteis às novas gerações que se preparam para o universo do ensino superior. Além do âmbito familiar, participar das assembleias indígenas, nas aldeias, com essa bagagem de conhecimentos novos, redigir documentos, debater com as lideranças e comunidades sobre temas relevantes, pensar sobre componentes e práticas das culturas tradicionais que precisam ser refletidos, revitalizados e ressignificados, como, por exemplo, o papel secundário que as mulheres muitas vezes ocupam nas instâncias de poder... esses são os grandes resultados para as mulheres, os povos indígenas, suas culturas e sua história. 


\section{Referências}

BANCO MUNDIAL. FLACSO. Exclusão social e redução da pobreza na América Latina e Caribe. São José: FLACSO: Banco Mundial, 2000.

BRASIL. Ministério dos Negócios da Fazenda. Decisão № 119, de 16 de abril de 1872. Indefere o pedido de alguns Índios do aldeamento existente em Cabo Frio, relativamente a educação superior de seus filhos. Collecção da Decisões do Governo do Império do Brasil de 1872. Rio de Janeiro: Typographia Nacional, 1973. p. 112. Tomo XXXV.

BENGOA, José. Desarrollo con identidad: la cuestion del desarrollo indígena en America Latina. In: UQUILLAS, Jorge.E.; RIVERA, Jean-Carlo. Pueblos indígenas y desarrollo en America Latina. Washington: Banco Mundial, 1993. P.73-82.

C. B. [Entrevista cedida a] Maria Simone Jacomini Novak. Formação superior indígena. Maringá, jan. 2014. Informação oral.

CAVUSCENS, Silvio. Vídeo aula 10: Movimentos indígenas, as estratégias e as lutas na conquista de direitos. [Rio de Janeiro: Laced, 2014]. 1 vídeo (63 min). Disponivel em: http://laced3.hospedagemdesites.ws/laced/acervo/videoaulas/o-estado-e-os-povos-indigenas-no-brasil/videoaula-10-movimentosindigenas-as-estrategias-e-as-lutas-na-conquista-de-direitos/. Acesso em: 15 abr. 2020.

CEPAL. Mujeres indígenas en América Latina: dinámicas demográficas y sociales em el marco de los derechos humanos. Santiago do Chile: Cepal, 2013. 159 p. (Colección Documentos de proyectos). Disponível em: https://repositorio.cepal.org/bitstream/handle/11362/4100/1/S2013792_es.pdf. Acesso em: 20 mar. 2020.

CLADEM. La participación de las mujeres indígenas em la conservación del patrimonio cultural. Paraguai: Cladem, 2014. Disponível em: https://www.ohchr.org/Documents/Issues/IPeoples/EMRIP/CulturalHeritage/CLA DEM_sp.pdf. Acesso em: 10 ab. 2020.

COLLET, Celia Letícia Gouvêa. Interculturalidade e educação escolar indígena: um breve histórico. Formação de professores indígenas repensando trajetórias. Brasília: MEC/SECAD-UNESCO, 2006. p. 115-130.

DAVIS, Shelton. Indigenous peoples, poverty and participatory development: the experience of the World Bank in Latin America. Georgetown University, Scholl of Foreign Service,Entrecaminos Spring 2003, I. 
DURSTON, J. Los grupos indígenas y el desarrollo social. Proyeto de desarrollo social e rural. [S.L.]: Biblioteca da CEPAL, 1979. Disponível em:

http://repositorio.cepal.org/bitstream/handle/11362/32332/S7900664_es.pdf?seq uence=1\&isAllowed=y. Acesso em: 15 abr. 2017.

FAUSTINO, Rosângela Célia. Política educacional nos anos de 1990: o multiculturalismo e a interculturalidade na educação escolar indígena. 2006. 334 f. Tese (Doutorado em Educação) - Centro de Ciências da Educação. Universidade Federal de Santa Catarina, 2006.

FAUSTINO, Rosângela Célia. Movimentos sociais, questão indígena e educação no contexto da diversidade cultural. Revista Contrapontos - Eletrônica, v. 11, n. 3, p. 323-335, Itajaí, 2011. Disponível em:

https://siaiap32.univali.br/seer/index.php/rc/article/view/2952. Acesso em 15 ab. 2020.

FAUSTINO, Rosângela Célia; NOVAK, Maria Simone Jacomini; CIPRIANO, Suzan Carneiro Vanfej. A presença indígena na universidade: acesso e permanência de estudantes Kaingang e Guarani no Ensino Superior do Paraná. Revista Cocar, Belém: UEPA, v. 7, p. 69-81, 2013.

GAGLIARDI, J. M. O indígena e a república. São Paulo: Hucitec, 1989.

GEHRKE, Marcos; SAPELLI, Marlene Lucia Siebert; FAUSTINO, Rosangela Celia. A formação de pedagogos indígenas em alternância no Paraná: uma contribuição à interculturalidade e ao bilinguismo. Revista Brasileira de Educação do Campo, v. 4, p. e7350-e7350. Palmas, 2019. Disponível em:

https://sistemas.uft.edu.br/periodicos/index.php/campo/article/view/7350/16093 . Acesso: 15 ab. 2020)

HARTMANN; Roswith.; OBEREM, Udo. Quito: Un centro de educación de indígenas em El siglo XVI. In: HARTMANN, Tekla.; COELHO, Vera Penteado. et. al. Contribuições à antropologia em homenagem ao professor Egon Schaden. São Paulo: [s.n.] 1981. (Coleção Museu Paulista, Série Ensaios, v. 14).

IBGE. Censo demográfico 2010. [Rio de Janeiro, IBGE, 2010]. Disponível em: www.ibge.gov.br. Acesso em: 08 nov. 2012.

J.S. [Entrevista cedida a] Maria Simone Jacomini Novak. Formação superior indígena. Maringá, jan. 2014. Informação oral.

M.A. [Entrevista cedida a] Maria Simone Jacomini Novak. Formação superior indígena. Maringá, jan. 2014. Informação oral. 
MARQUI, Amanda Rodrigues; OLIVEIRA, Lúcia A. Andrade de. A formação de professores indígenas no Brasil: relato das experiências do Programa de Apoio à Formação Superior e Licenciaturas Indígenas (Prolind). In: JANEIRO, Cassia.

Diversidades. Rio de Janeiro: FLACSO Brasil, 2019, p. 32-42). (Série Cadernos FLACSO, no 15) Disponível em: http://flacso.org.br/files/

2019/12/Caderno_FLACSO_N15.pdf. Acesso em: 15 abr. 2020.

MATOS, Maria Helena Ortolan. Rumos do movimento indígena no Brasil contemporâneo: experiências exemplares no Vale do Javari. 2006. 274 f. Tese. (Doutorado em Ciências Sociais) - Unicamp, Campinas, 2006.

MINAYO, Maria Cecília de Souza. Ciência, técnica e arte: o desafio da pesquisa social. In: MINAYO, Maria Cecília de Souza (org.). Pesquisa social: teoria, método e criatividade. Petrópolis: Vozes, 2000.

MONTEIRO, Jonh Manuel. Negros da terra: índios e bandeirantes nas origens de São Paulo. São Paulo: Companhia das Letras, 1994.

MOTA, Lúcio Tadeu. O aço, a cruz e a terra: índios e brancos no Paraná Provincial 1853/1889. 1998. 531 f. Tese (Doutorado em História) - Programa de Pós Graduação em História. UNESP, Assis, 1998.

NOVAK, Maria Simone Jacomini. Política de ação afirmativa: a inserção dos indígenas nas universidades públicas paranaenses. 2007. 135 f. Dissertação (Mestrado em Educação) - Programa de pós-graduação em Educação da Universidade Estadual de Maringá, Maringá, 2007.

NOVAK, Maria Simone Jacomini. Os organismos internacionais, a educação superior para indígenas nos anos de 1990 e a experiência do Paraná: estudo das ações da Universidade Estadual de Maringá. 2014. 342 f. Tese (Doutorado em Educação) - Universidade Estadual de Maringá, Maringá, 2014.

OLIART, Patricia. Las organizaciones de mujeres indígenas em Perú y los discursos de los derechos indígenas y La equidad de género. In: Hernández, Aída Rosalba; Canessa, Andrew (ed.) Complementariedades y exclusiones em Mesoamérica y los Andes. [S.L.]: IWGIA, 2012. (Serie Testimonios).

OLIVEIRA FILHO, João Pacheco de; ROCHA FREIRE, Carlos Augusto de. A presença indígena na formação do Brasil. [S.l.]: UNESCO, 2006.

ONU. Organização das Nações Unidas. Declaracion sobre los derechos de las personas pertenecientes a minorias nacionales o etnicas, religiosas y linguisticas. Genebra: [ONU], 1992. 
OIT. Organização Internacional do Trabalho. Trabalho docente e juventude: América Latina; Resumo Executivo. Brasília: [OIT], 2007.

OIT. Organização Internacional do Trabalho. Convenção no. 107 de 05 de junho de 1957. [Brasília: OIT], 1957. Disponível em:

http://www.trtsp.jus.br/geral/tribunal2/LEGIS/CLT/OIT/OIT_107.html. Acesso em: 21 fev. 2014.

PARANÁ, Superintendência Geral de Ciência, Tecnologia e Ensino Superior (SETI). Relatório do Vestibular dos Povos Indígenas no Paraná. [Curitiba: SETI], 2020. Disponível em: file:///C:/Users/Micro/Documents/ relatorio_vestibular_indigena.pdf. Acesso em: 7 abr. 2020.

PARANÁ, Dia a dia da educação. Consulta escolas 2019. [Curitiva: Secretaria da Educação e do Esporte], 2019. Disponível em: http://www.consultaescolas.pr.gov.br/consultaescolasjava/pages/templates/initial2.jsf?windowld=ac4. Acesso em: 22 jan. 2020.

PARANÁ. Resolução Conjunta SETI 006 - 26 de Junho de 2007. [Aprova] Resolução Conjunta 006 - SETI/UEL/UEM/UEPG/UNIOESTE/UNICENTRO/ UNESPAR/UENP/UFPR. Diário Oficial do Estado do Paraná, n. 7500, 26 jun. 2007. Disponivel em: https://www.legislacao.pr.gov.br/legislacao/ pesquisarAto.do?action=exibir\&codAto=82875. Acesso em: 10 abr. 2020.

PARTRIDGE, William. L; UQUILLAS, Jorge. E.; JOHNS, Kathryn. Including the excluded: ethno development in Latin America. In: II Annual World Bank Conference on Development in Latin America and the Caribbean. Bogota Colombia, World Bank, 1996. Disponível em: http://documents.worldbank.org/curated/en/981431468770397760/Includingthe-excluded-ethnodevelopment-in-Latin-America. Acesso em: 5 jul. 2005.

PAULINO, Marcos M. Povos indígenas e ações afirmativas: o caso do Paraná. 2008. 162 f. Dissertação (Mestrado em Educação) - Universidade Federal do Rio de Janeiro, Rio de Janeiro, 2008.

PNUD. Relatório do Desenvolvimento Humano 2014: sustentar o progresso humano: reduzir as vulnerabilidades e reforçar a resiliência. Camões: Instituto da Cooperação e da Língua, 2014. Disponível em: http://hdr.undp.org/sites/ default/files/hdr2014_pt_web.pdf. Acesso em: 10 maio 2015.

PSACHAROPOULOS, George; PATRINOS, Harry Anthony (eds.). Indigenous people and poverty in Latin América: an empirical analysis. Washington: Banco Mundial, 1993. $256 \mathrm{p}$. 
RAMOS, Alcida Rita. Constituições nacionais e povos indígenas. Belo Horizonte: Editora da UFMG, 2012.

RIES, Nicholas M; HUGUES, John.; SAER, D.J. El bilinguismo y la educación: ediciones, la lectura. Madrid: Espasa Calpe, 1932.

RODRIGUES, Isabel Cristina. VĒNH JYKRE SI: memória, tradição e costume entre os Kaingang da T.I. Faxinal - Cândido de Abreu - PR. 2012. 155 f. Tese

(Doutorado em Ciências Sociais). Pontifícia Universidade Católica de São Paulo, São Paulo, 2012.

RODRIGUES, Isabel Cristina; WAWZYNIAK, João Valentin. Inclusão e permanência de estudantes indígenas no ensino superior público no Paraná: reflexões. 2011.Disponível em: http://flacso.org.br/?publication=inclusao-e-permanenciade-estudantes-indigenas-no-ensino-superior-publico-no-parana-reflexoes. Acesso em: 15 ab. 2020

RUIZ, Siboney Pineda. La mujer indígena: ante la pobreza. Espacio Abierto,. Universidad Del Zulia, Maracaibo, v. 11, n. 2, p. 251-264, abr./jun. 2002.

S.C.C. [Entrevista cedida a] Maria Simone Jacomini Novak. Formação superior indígena. Maringá, jan. 2014. Informação oral.

S. M. [Entrevista cedida a] Maria Simone Jacomini Novak. Formação superior indígena. Maringá, jan. 2014. Informação oral.

S.V. [Entrevista cedida a] Maria Simone Jacomini Novak. Formação superior indígena. Maringá, jan. 2014. Informação oral.

SACCHI, Ângela. Mulheres indígenas e participação política: a discussão de gênero nas organizações de mulheres indígenas. Revista AntHropológicas, Pernambuco, ano 7, v. 14, n.1/2, p.95-110, 2003.

SACCHI, Ângela. Mulheres Indígenas: o processo organizativo e as demandas de gênero. In: Verdum. Ricardo. (org). Assistência técnica e financeira para o desenvolvimento indígena: possibilidades e desafios para políticas públicas. Brasília: Contra Capa Livraria, 2005.

SANTOS, Juliana S.; SCHILLING, Flávia. Direitos humanos, igualdade e diferença: as tensões em torno das relações de gênero no movimento zapatista. 2008.

Revista ORG \& DEMO, Marília, v.9, n.1/2, p. 75-94, jan./dez. 2008. 
SILVA NOVAK, Éder da; MOTA, Lúcio Tadeu. A política indigenista e os territórios indígenas no Paraná (1900-1950). Fronteiras, Dourados, v. 18, n. 32, p. 76-97, 2016.

SILVA, Paulo de Tássio Borges da. Diferença, interculturalidade e autosustentação na educação escolar indígena pataxó. Revista Tempos e Espaços em Educação. Aracaju, v. 5, n. 9, p. 99-109, 2012.

UNESCO. Conferência mundial de educação superior. [S.l:: UNESCO], 1998. Disponivel em: http://www.interlegis.gov.br/processo_legislativo/ copy_of_20020319150524/20030620161930/20030623111830. Acesso em: 26 out. 2016.

UNESCO. A declaração das raças da UNESCO. [S.l:: UNESCO], 18 jul. 1950. Disponivel em: http://www.achegas.net/numero/nove/decla_racas_09.htm. Acesso em: 15 maio 2013.

VERDUM, Ricardo. (org.) Mulheres indígenas, direitos e políticas públicas. Brasília: Inesc, 2008.

WIEVIORKA, Michel. Será que o multiculturalismo é a resposta?

Porto, Educação, Sociedade \& Culturas, n. 12, 1999. 